\title{
The Impact Compression Behaviors of Silica Nanoparticles-Epoxy Composites
}

\author{
Pibo Ma*, Gaoming Jiang*, Yanyan Li, Wenxin Zhong \\ Engineering Research Center for Knitting Technology, Jiangnan University, Wuxi, China \\ Email: "
}

Received 7 November 2014; accepted 19 November 2014; published 16 January 2015

Copyright (C) 2015 by authors and Scientific Research Publishing Inc.

This work is licensed under the Creative Commons Attribution International License (CC BY). http://creativecommons.org/licenses/by/4.0/

c) (i) Open Access

\begin{abstract}
The compressive properties of epoxy with different silica nanoparticles ( $\mathrm{SiO}_{2}$ nanoparticles) contents at quasi-static and high strain rates loading were investigated via experiment. This article evaluates the compressive failure behaviors and modes at different $\mathrm{SiO}_{2}$ nanoparticles contents and different strain rates. The results indicated that the stress strain curves were sensitive to strain rate, and the compressive failure stress of composites with various $\mathrm{SiO}_{2}$ nanoparticles contents increased with the strain rates, and it increased along with $\mathrm{SiO}_{2}$ nanoparticles contents and then declined. The compressive failure stress and the compressive failure modes of the composites were apparently different from the change of $\mathrm{SiO}_{2}$ nanoparticles contents.
\end{abstract}

\section{Keywords}

Impact Compression Behaviors, Silica Nanoparticles, Composites, Strain Rate

\section{Introduction}

Epoxy has been used widely for the matrices of textile structural reinforced polymer composites, because epoxy polymers have excellent mechanical performances such as high modulus and high failure strength and good adhesion with fibers. However, epoxy polymers also have some undesirable properties such as poor resistance to crack initiation and growth due to their brittle property.

The property improvement of epoxy polymers are increasing with the developing of fiber reinforced composites. Rosso et al. [1] investigated the mechanical properties of silica/epoxy nanocomposites, they found that the stiffness and facture energy can be improved $20 \%$ and $140 \%$ with increasing of 5 vol\% silica nanoparticles. Johnsen et al. [2] also researched the silica/epoxy nanocomposites, in their researches, the facture energy can be increased to $250 \%$ for the epoxy nanocomposites with 5 vol\% silica nanoparticles. Deng et al. [3] investigated

\footnotetext{
Corresponding authors.
} 
that the fracture property of silica/epoxy nanocomposites at different temperatures from $-50^{\circ} \mathrm{C}$ to $70^{\circ} \mathrm{C}$, and the results showed that the fracture energy was greatly improved at $50^{\circ} \mathrm{C}$. Besides the silica/epoxy nanocomposites, many researchers also investigated the fiber reinforced epoxy with silica nanoparticles. Zheng et al. [4] studied the glass fibers reinforced epoxy/silica nanoparticles composites, and they found that the tensile properties and bending properties of the composites were obviously improved with the increasing of silica nanoparticles. Wang et al. [5] adopted the "slurry-compounding” process to prepare the epoxy nanocomposites with highly exfoliated clay. The results indicated that Young's modulus increased monotonically with increasing the clay concentration and fracture toughness reached the maximum at $2.5 \mathrm{wt} \%$ of clay. Zhou et al. [6] analysis the thermal and mechanical properties of the carbon fiber reinforced clay/epoxy composites. To their analysis, the $2.0 \mathrm{wt} \%$ clay filled epoxy showed the highest enhancement in flexural strength. At the same time, the $2.0 \mathrm{wt} \%$ systems exhibited the highest storage modulus. Ferreira et al. [7] investigated the fatigue behaviors of Kevlar composites with nanoclay-filled epoxy resin, they found that the filled composites showed tensile fatigue strength $12 \%$ higher than unfilled matrices, but in three-point bending the fatigue strength of filled composites was lower. Barbezat et al. [8] researched the fracture properties of GFRP laminates with nanocomposite epoxy resin matrix, to their researches, the static and dynamic fracture properties of the GFRP laminates were negatively influenced by the modification of the matrix with the organo-silicate. Uddun et al. [9] analysis that the strength of undirectional glass/epoxy composite with silica nanoparticle-enhanced matrix, they found that the silica nanoparticles could dramatically increase the longitudinal compressive strength and moderately increase the longitudinal and transverse tensile strength. Tsai et al. [10] investigated the mechanical properties of silica nanoparticle reinforced composites, the results showed that the extent of the silica nanopsrticles were more appreciable in the brittle matrix system rather than in the ductile matrix systems. To the glass fiber/silica/epoxy composites, the inplane shear strength increased until the nanoparticle loading was up to $10 \mathrm{wt} \%$. Ma et al. [11]-[13] researched the transverse behaviors and compressive behaviors of nanoparticles reinforced composites under high strain rates.

The mechanical properties of the composites are greatly influenced by the length scale of component phase. Above researches also show that the mechanical properties of epoxy with silica nanoparticles can be improved obviously. However, the strain rates effect of epoxy with silica nanoparticles is still beyond our attentions. For the applications of impact resistance and impact protection, the mechanical parameters of the composite at high strain rates should be introduced because the composites often manifest the strain rate sensitivity. In this research, the epoxy with various contents of $\mathrm{SiO}_{2}$ nanoparticles was prepared. The compression behaviors of the nanocomposites under quasti-static and high strain rates conditions will be presented. The compression strength, failure strain, energy absorption, compression stiffness and failure modes of various $\mathrm{SiO}_{2}$ contents nanocomposites under different compression strain rates also will be investigated.

\section{Experimental Procedure}

\subsection{Materials}

The epoxy resin was Type 618 made by Shanghai Resin Factory of China, tensile modulus: 1.97 GPa, tensile strength: $68.10 \mathrm{MPa}$. The $\mathrm{SiO}_{2}$ partiles were spherical particles supplied by Zhejiang Hongsheng Rial Technilogy Co., Ltd. The particle size of the $\mathrm{SiO}_{2}$ nanoparticles was $20-50 \mathrm{~nm}$, the specific surface area was $160 \pm 20$ $\mathrm{m}^{2} / \mathrm{g}$, the bulk density was smaller than $0.11 \mathrm{~g} / \mathrm{cm}^{3}$ and the purity being greater than $98.5 \mathrm{wt} \%$.

\subsection{Preparation of $\mathrm{SiO}_{2}$ Nanoparticles-Filled Epoxy Resin}

$\mathrm{TheSiO}_{2}$ nanoparticles were put in acetone solution. The concentration of $\mathrm{SiO}_{2}$ nanoparticles was set at 0 wt\%, 5 wt\%, $10 \mathrm{wt} \%$ or $15 \mathrm{wt} \%$, and the mixture was ultra sonicated by an ultrasonic cell disruptor BILON92-IID (Shanghai Bilang)for about 6 hours in order to get a homogenous solution. Then the mix of Bisphenol A epoxy (Type 618 made by Shanghai Resin Factory of China) was added to the solution and stirred at $40^{\circ} \mathrm{C}$ for 12 hours.

\subsection{Composites Fabricating}

The composites were fabricated with the $\mathrm{SiO}_{2}$ nanoparticles filled-epoxy resin through a special box. The mix of Bisphenol A epoxy with $\mathrm{SiO}_{2}$ nanoparticles and agent Tri-methyl-hexamethylene-diamine (Type 593 made by Shanghai Resin Factory of China) in the volume proportion of 3:1.

The composite coupons for testing were prepared according to the length $\times$ width is $9 \mathrm{~mm} \times 9 \mathrm{~mm}$, and the 
thickness is $5 \mathrm{~mm}$.

\subsection{Compression Tests under Various Strain Rates}

The compression tests were conducted under both quasi-static and high strain rates. Strain rate is the rate of change in strain (deformation) of composites with respect to time. For the strain rate at high rates of straining,

$$
\dot{\varepsilon}(t)=\frac{\mathrm{d} \varepsilon}{\mathrm{d} t}=\frac{\mathrm{d}}{\mathrm{d} t}\left(\frac{L(t)-L_{0}}{L_{0}}\right)=\frac{1}{L_{0}} \frac{\mathrm{d} L}{\mathrm{~d} t}(t)=\frac{v(t)}{L_{0}}
$$

where $\dot{\varepsilon}(t)$ is strain rate, $\varepsilon$ is the strain, $L_{0}$ is the original length, $L(t)$ is the length at each time, $v(t)$ is the speed at which the ends are moving away from each other.

For the strain rate in quasi static, the approximate strain can be calculated from follow equation,

$$
\dot{\varepsilon}(t)=\frac{v}{L}
$$

where $\dot{\varepsilon}(t)$ is strain rate, $v$ is the speed of compression, $L$ is the length of sample. The compression test under the quasi-static condition was performed on an MTS810.23 system at a speed of $1 \mathrm{~mm} / \mathrm{min}$.

The high strain rate compression tests were carried out on a split Hopkinson pressure bar (SHPB) apparatus. The schematic illustration and principle of the SHPB employed in this study are shown in Figures 1-3 respectively. A small specimen is between two elastic bars of the same cross sectional area and modulus, which are named as the incident bar and transmission bar separately. The material of the striker and pressure bars is steel subjected to maraging with extremely high yield strength in order to withstand a very high impact velocity. An elastic stress pulse is imparted to the incident bar by impacting it with a striker bar of the same cross sectional area and modulus. The impact of the striker bar generates as elastic stress wave with twice the length of the striker bar and propagates through the incident bar with the velocity of sound in the bar media and passes through the specimen while deforming it. The particle velocity imparted on the incident bar is half the impact velocity of the striker bar. The stress in the bar is given by

$$
\sigma=\rho C_{0} v_{P}
$$

where $\rho$ is the density of the bar material, $C_{0}$ is the bar sonic velocity and $v_{P}$ is the particle velocity.

When the elastic wave reaches the specimen-incident bar interface, part of it will be reflected back, and part of it will be transmitted through the specimen and pass through the transmission bar. To acquire the direct incident pulse, the reflected pulse and the transmitted pulse, strain gauges are mounted on both the incident and transmission bars. One-dimensional wave propagation is assumed to analyze the strain signals from the strain gauges (Type $\mathrm{BF}(\mathrm{BH}) 350-8 \mathrm{KA}$ made by Shanghai Shendi Informational Technology Co., Ltd.).

If $E_{b}, A_{b}$ and $\rho_{b}$ represent the modulus, cross section area and density of the bar and $E_{s}, A_{s}$ and $\rho_{s}$

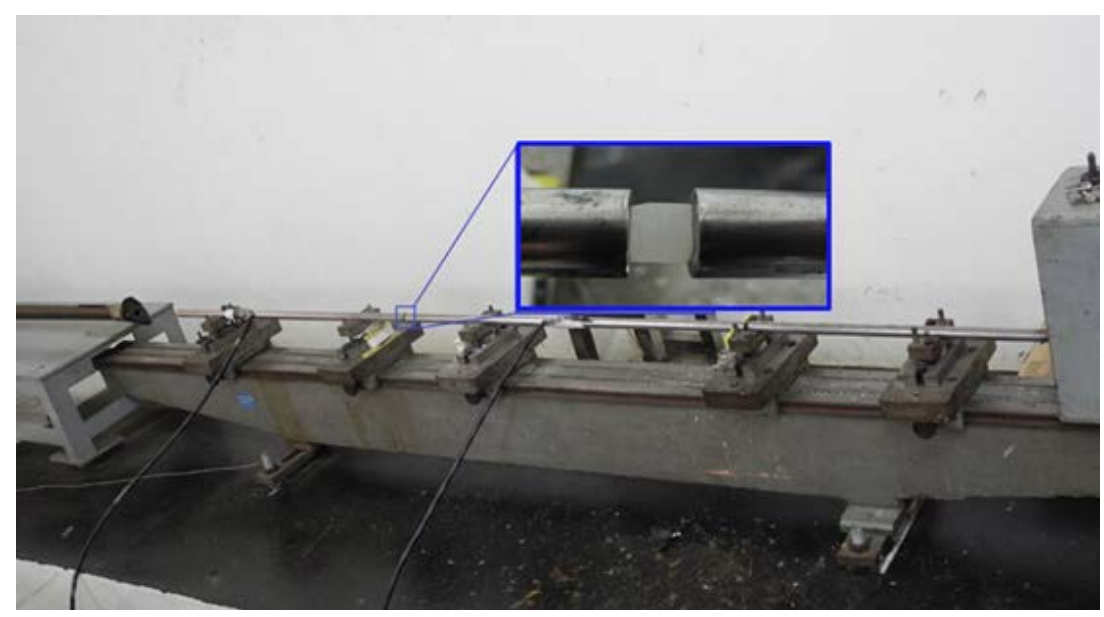

Figure 1. Set-up of split Hopkinson pressure bar. 


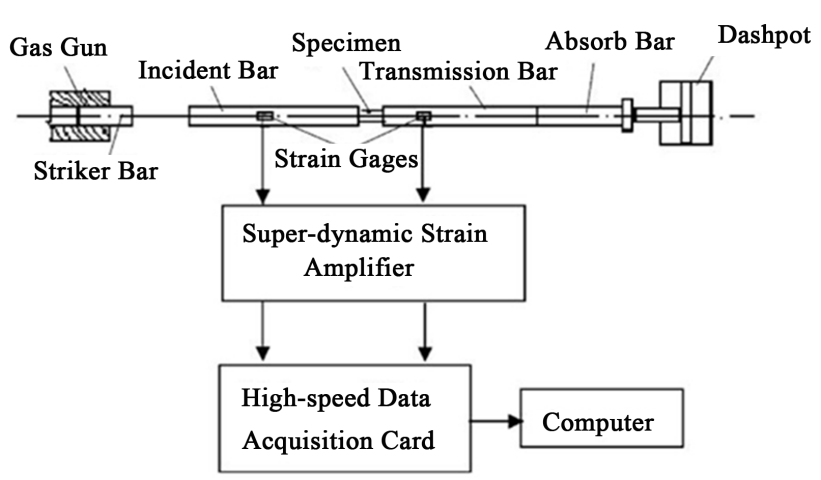

Figure 2. Schematic of split Hopkinson pressure bar.

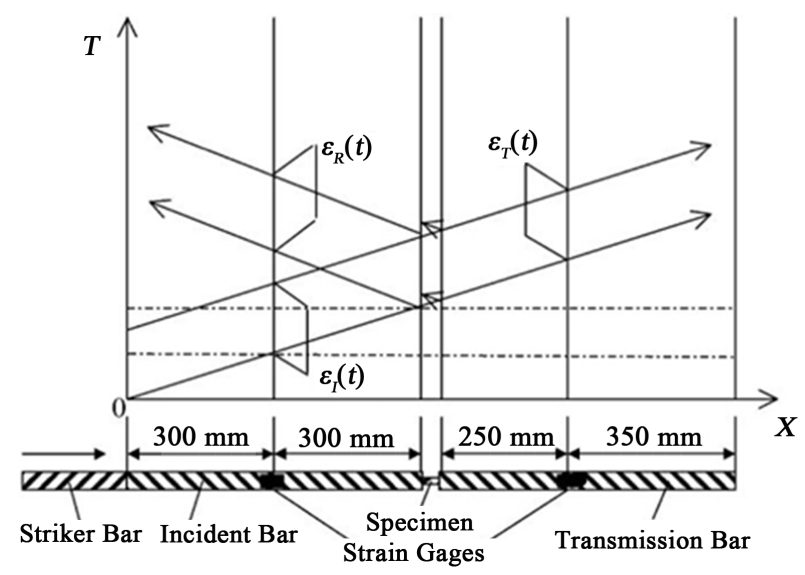

Figure 3. Principle of split Hopkinson pressure bar.

those of specimen then the equations for the strain rates $(\dot{\varepsilon})$, strain $(\varepsilon)$ and stress $(\sigma)$ of the specimen are as follows:

$$
\begin{gathered}
\dot{\varepsilon}(t)=-\frac{2 C_{0}}{L_{s}} \varepsilon_{R}(t) \\
\varepsilon(t)=-\frac{2 C_{0}}{L_{s}} \int_{0}^{t} \varepsilon_{R}(t) \mathrm{d} t \\
\sigma(t)=\frac{E_{b} A_{b}}{A_{s}} \varepsilon_{T}(t)
\end{gathered}
$$

where, $C_{0}=\sqrt{E_{b} / \rho_{b}}$ represents the longitudinal wave velocity in the bar;

$L_{s}$ represents the specimen length;

$\varepsilon_{R}(t)$ and $\varepsilon_{T}(t)$ are the strain gauge signals of the reflected and the transmitted pulses, respectively.

The average stress and strain in the specimen can be known as a function of time and the mechanical properties of the composite, such as strain rates and stress-strain behavior, along the loading direction can be determined from Equations (4)-(6).

The SHPB employed in this study was equipped with a momentum trapping device, a gas gun of $14.5 \mathrm{~mm}$ inner diameter. The diameter of the incident and transmission bars was the same (diameter $14.5 \mathrm{~mm}$ and length $600 \mathrm{~mm}$ ). Compressed nitrogen gas was employed to operate the gas gun and propel the striker bar to move a distance of $200 \mathrm{~mm}$. The impact velocity of the gas gun (strike bar) could be changed by changing gas pressure to get required strain rates. The schematic and principle of split Hopkinson pressure bar are shown in Figure 2 and Figure 3 respectively. 


\section{Results and Discussion}

\subsection{Stress-Strain Relations}

Compression tests of epoxy composites with various $\mathrm{SiO}_{2}$ nanoparticles contents were conducted at different strain rates. As above-mentioned, at least five samples were tested at each strain rate (including quasi-static state). Figure 4 shows the typical signals obtained from the input and output bar for $5 \mathrm{wt} \% \mathrm{SiO}_{2}$ nanoparticles contents at strain rate of 1600/s conditions. According to the one dimensional stress wave propagation theory of the SHPB apparatus, the stress strain curves under high strain rates can be calculated. The results are shown in Figures 5-8. It can be observed that the stress-strain curves are sensitive to strain rate for different $\mathrm{SiO}_{2}$ nanoparticles contents.

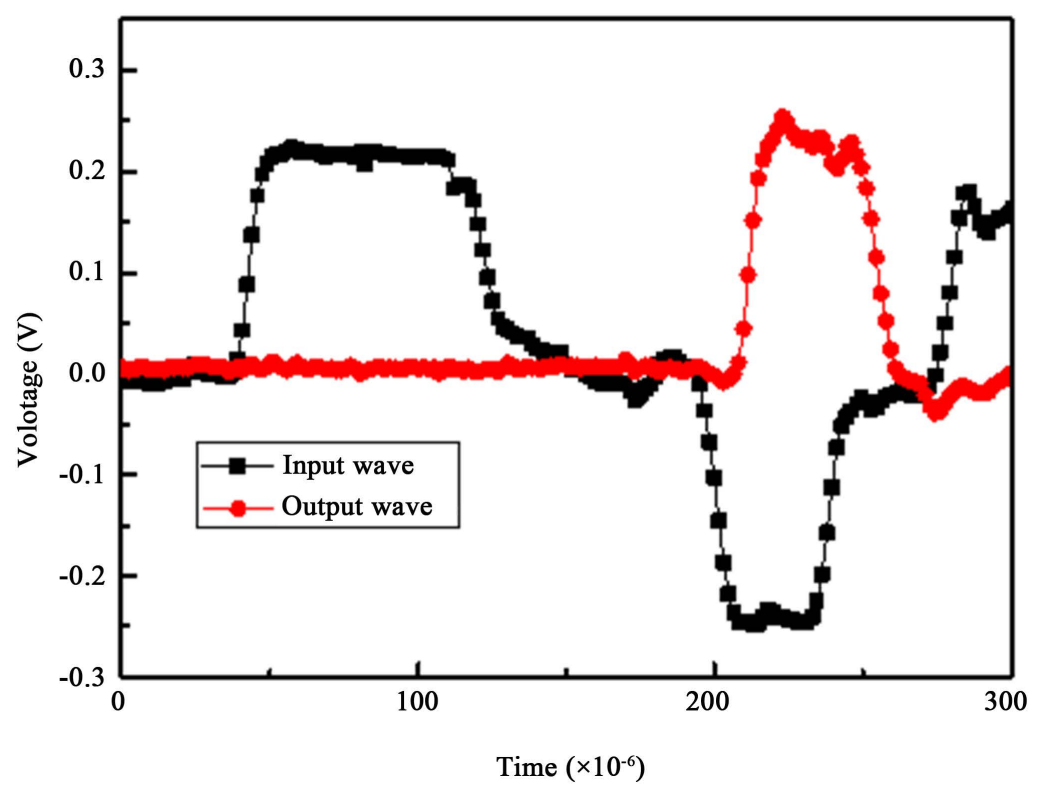

Figure 4. Typical signals in input and output bar under compression with 5 wt\% $\mathrm{SiO}_{2}$ at strain rate of $1600 /$ s.

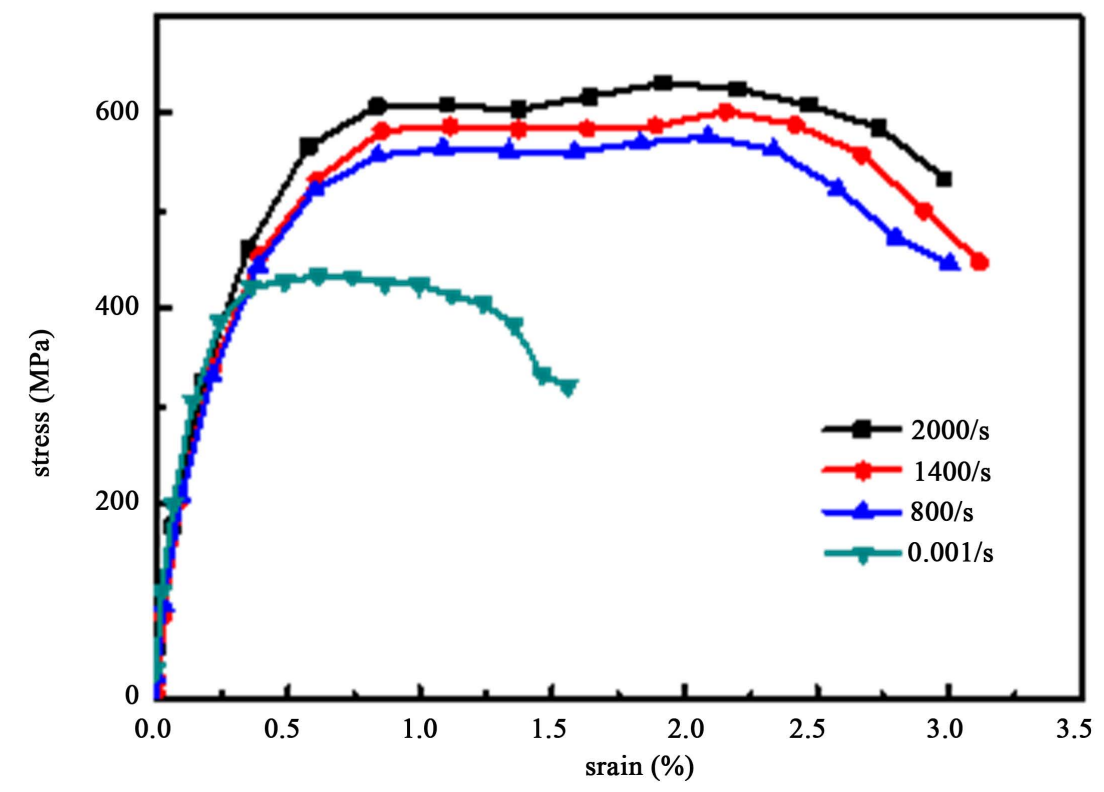

Figure 5. Stress-strain curves of epoxy/ $\mathrm{SiO}_{2}(0 \mathrm{wt} \%)$ composites at various strain rates. 


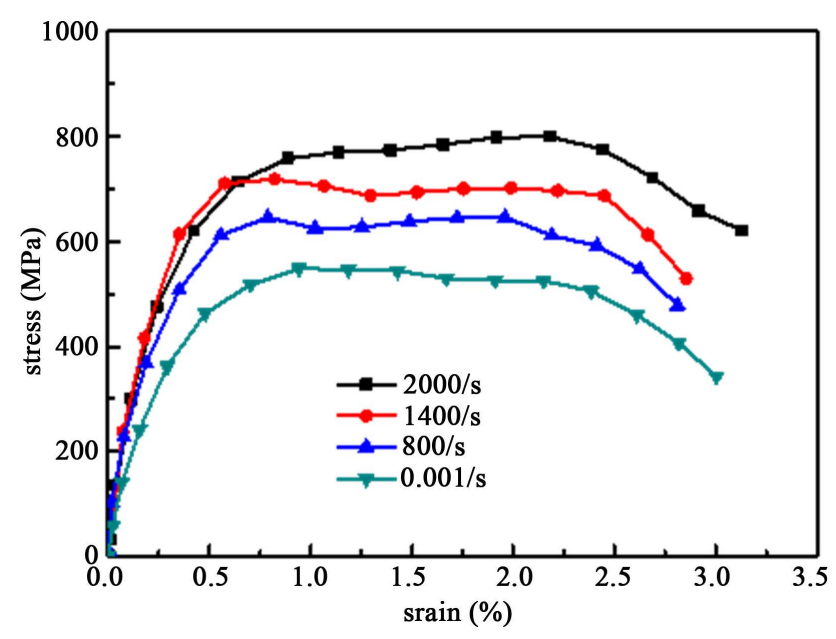

Figure 6. Stress-strain curves of epoxy/SiO 2 (5 wt\%) composites at various strain rates.

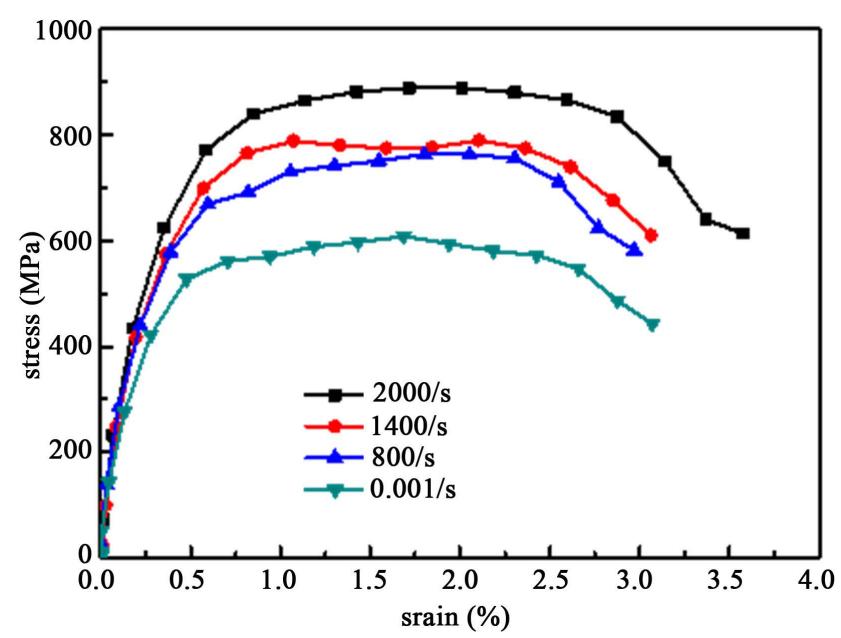

Figure 7. Stress-strain curves of epoxy/SiO 2 (10 wt\%) composites at various strain rates.

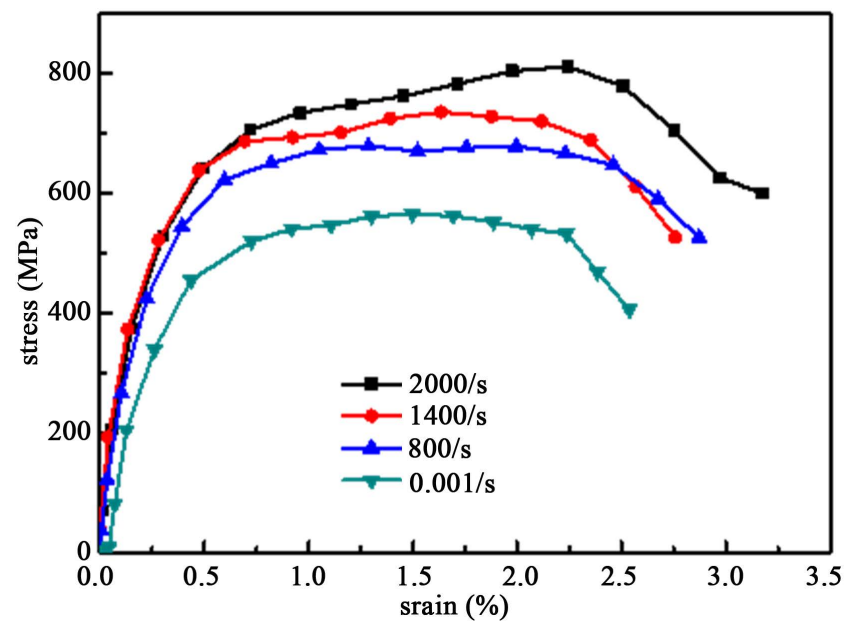

Figure 8. Stress-strain curves of epoxy/SiO 2 (15 wt\%) composites at various strain rates. 
Figure 5 shows the stress-strain curves of epoxy without $\mathrm{SiO}_{2}$ nanoparticles at various strain rates. Figure 5 indicates that the compressive failure stress increases, the compressive stiffness decreases and the failure strain increases with increasing strain rate at high strain rate compression.

Figure 6 shows the stress-strain curves of epoxy composites with $5 \mathrm{wt} \% \mathrm{SiO}_{2}$ nanoparticles at various strain rates. Similar to Figure 5 which is for the composites without $\mathrm{SiO}_{2}$ nanoparticles, the compressive failure stress and compressive failure strain are increasing with increasing strain rate. And the stiffness of composites is increased with the $\mathrm{SiO}_{2}$ nanoparticles content increasing, because the $\mathrm{SiO}_{2}$ nanoparticles can increase the interface strain in the resin.

Figure 7 and Figure 8 are the stress-strain curves of epoxy composites with $10 \mathrm{wt} \% \mathrm{SiO}_{2}$ nanoparticles and $15 \mathrm{wt} \% \mathrm{SiO}_{2}$ nanoparticles at various strain rates, respectively. Similar with Figure 6, the compressive failure stress increases as the strain rate grows, the compressive failure strain also increases when strain rate increases at high strain rates compression. Meanwhile, the compressive stiffness of composites with $\mathrm{SiO}_{2}$ nanoparticles is larger than that of the composites without $\mathrm{SiO}_{2}$ nanoparticles. However, it can be found that the compressive failure stress are decline after the $\mathrm{SiO}_{2}$ nanoparticles content is more than $10 \mathrm{wt} \%$.

\subsection{Mechanical Properties}

Figure 9 shows the compressive failure stress of epoxy composites with various $\mathrm{SiO}_{2}$ nanoparticles contents under different strain rates. It can be seen that the compressive failure stress increases with the strain rate, and it is increases along $\mathrm{SiO}_{2}$ nanoparticles contents at first and then decrease after the $\mathrm{SiO}_{2}$ content is $15 \mathrm{wt} \%$. For high strain rate loading, the failure stress of epoxy composites with various $\mathrm{SiO}_{2}$ nanoparticles contents is much larger than that in quasi-static loading.

Figure 10 shows the compressive failure strain of epoxy composites with various $\mathrm{SiO}_{2}$ nanoparticles contents under different strain rates. Similar to Figure 12, it can be seen that the compressive failure strain increases with the strain rate and $\mathrm{SiO}_{2}$ nanoparticles contents.

\subsection{Compression Fracture Features}

The photographs in Figures 11(a)-(d) display the fracture features of epoxy without $\mathrm{SiO}_{2}$ nanoparticles at various strain rates under compressive loading. It is found that breakage of epoxy specimen occur at various strain rates. As the strain rate increasing, the specimen is compressed into several pieces of fragment which is shown in Figure 12(d). The obvious beginning crack happens at the strain rate of 800/s, and drastic at the strain rate of 1400/s. The failure state of the sample without $\mathrm{SiO}_{2}$ nanoparticles at various strain rates under in-plane loading is shown in the figures. It is can be observed that the specimen is cracked because of the radicalized stress transmission though the little epoxy block.

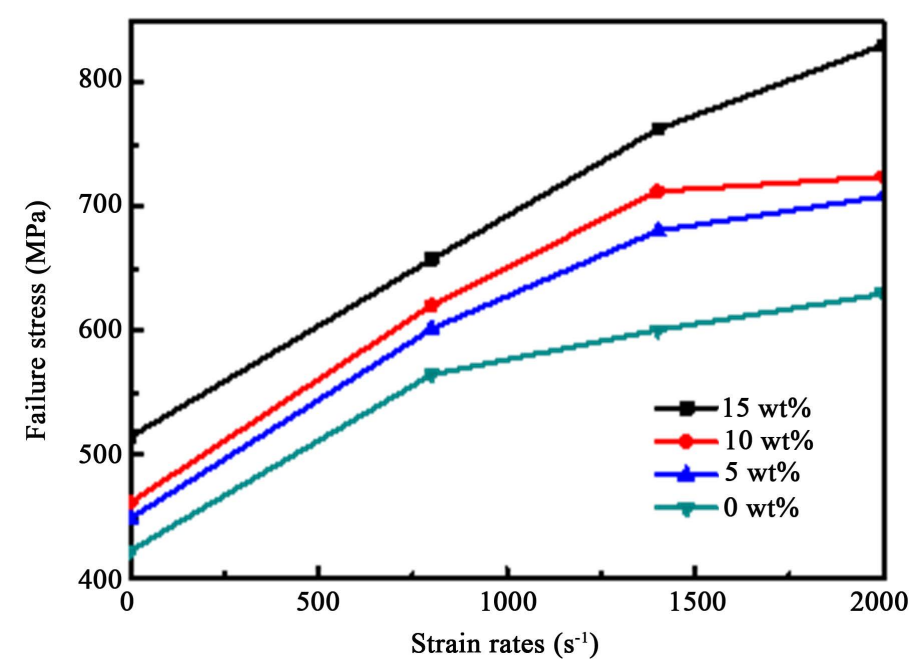

Figure 9. Failure stress of epoxy/ $/ \mathrm{SiO}_{2}$ (with different contents) composites at various strain rates. 


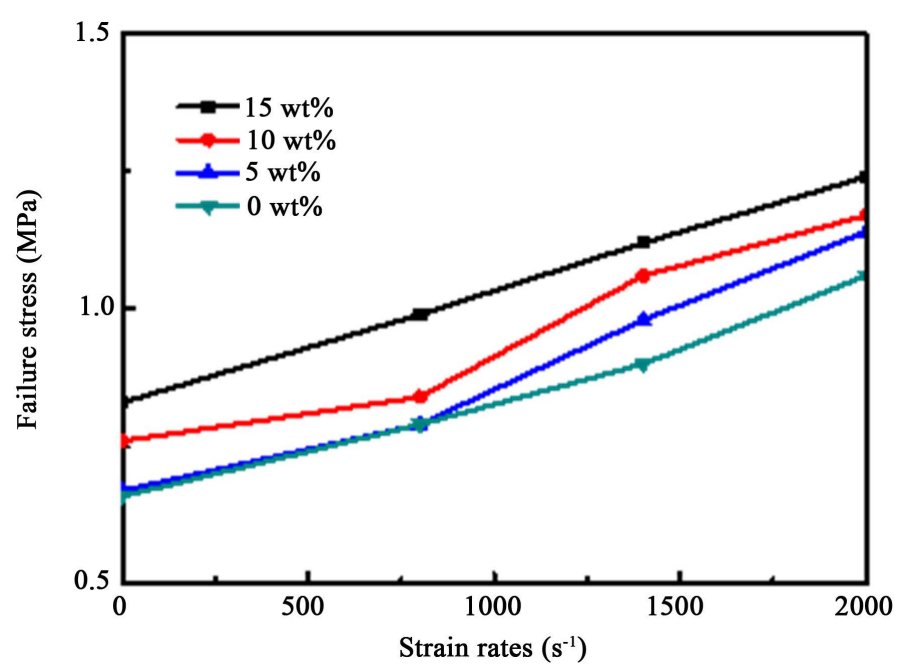

Figure 10. Failure strain of epoxy/SiO ${ }_{2}$ (with different contents) composites at various strain.

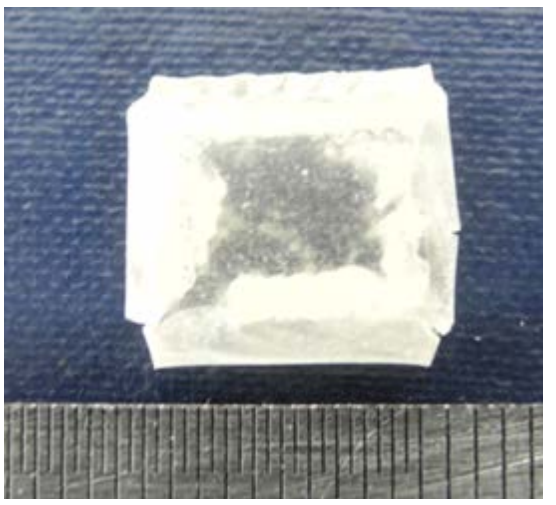

(a)

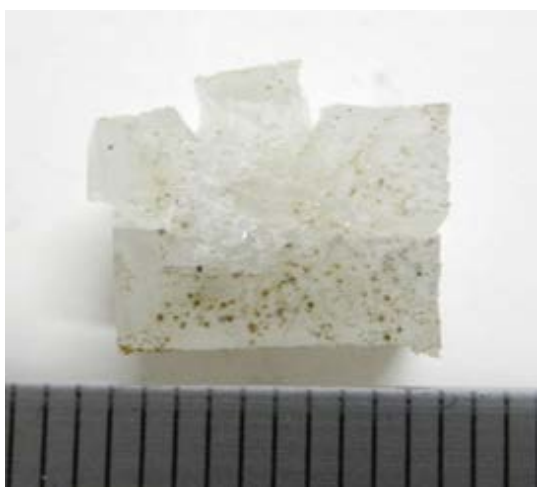

(c)

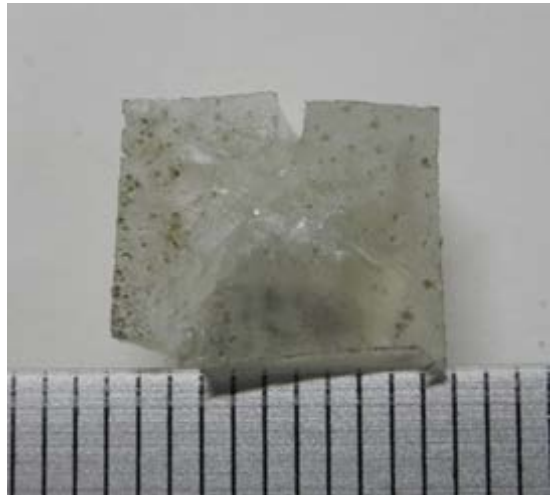

(b)

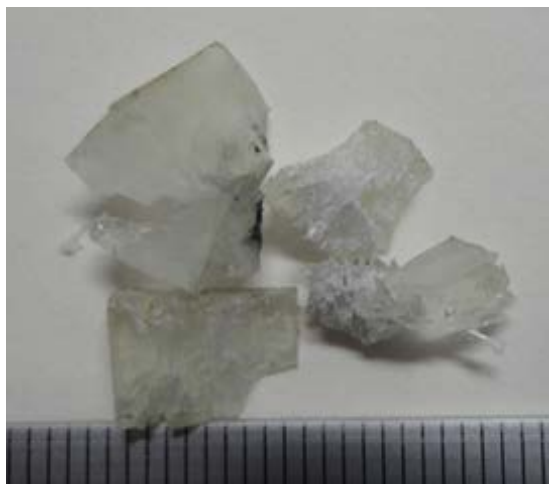

(d)

Figure 11. Compression fractures of epoxy/SiO 2 (0 wt\%) composites at various strain rates. (a) $0.001 / \mathrm{s}$; (b) $800 / \mathrm{s}$; (c) $1400 / \mathrm{s}$; (d) $2000 / \mathrm{s}$.

Figures 12(a)-(d) shows compression fractures of epoxy/ $\mathrm{SiO}_{2}$ nanoparticles (5 wt\%) composites at various strain rates. The crazes appear at the strain rate of 800/s, and the apparent crack arise at the strain rate of 1400/s. However, the specimen keeps as an entirety, instead of being the fragments, which is quite different from the state of the sample without $\mathrm{SiO}_{2}$ nanoparticles at the same strain rate. And then, at the strain rate of 2000/s, the composites fractured. The crack happens under high strain rate compression. 


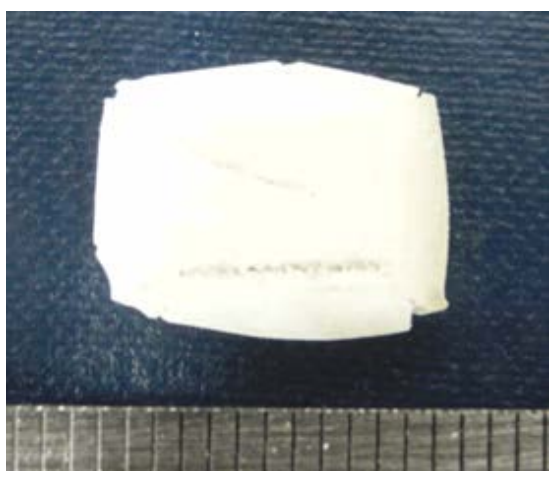

(a)

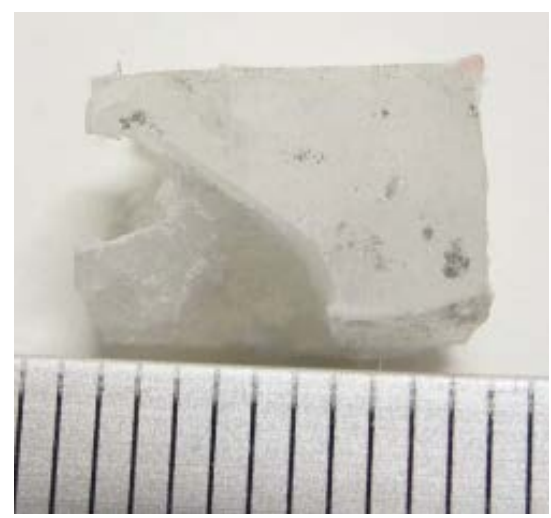

(c)

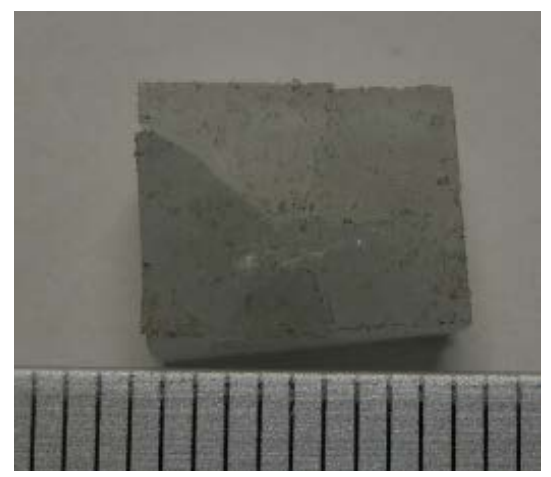

(b)

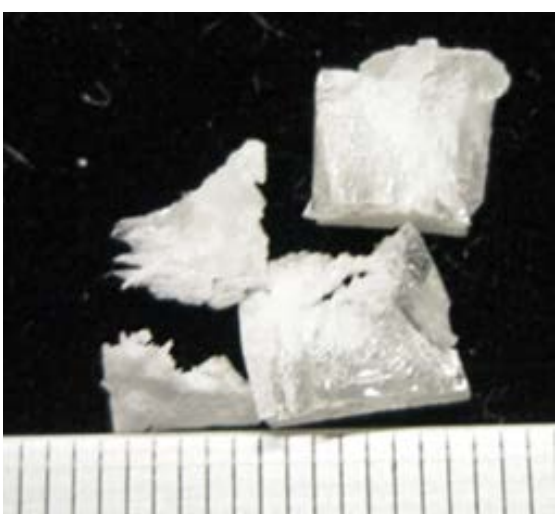

(d)

Figure 12. Compression fractures of epoxy/ $\mathrm{SiO}_{2}$ (5 wt\%) composites at various strain rates. (a) $0.001 / \mathrm{s}$; (b) $800 / \mathrm{s}$; (c) $1400 / \mathrm{s}$; (d) $2000 / \mathrm{s}$.

The photographs in Figure 13 illustrate compression fractures of epoxy/SiO $\mathrm{S}_{2}$ nanoparticles (10 wt\%) composites at various strain rates. It is found that the failure modes under quasi-static state and high strain rates are rather different. The performance of crack of is evidence under the strain rate of $0.001 / \mathrm{s}$. On the contrary, the morphological feature under the high strain rates is rather stable, which the shape of the specimen hardly change under 800/s and 1400/s expect a single craze, furthermore, the integrity of the sample is well kept ever under $2000 / \mathrm{s}$.

Compression fractures of epoxy/ $\mathrm{SiO}_{2}$ nanoparticles (15 wt\%) composites at various strain rates is shown in Figures 14(a)-(d). Similar with the situation of epoxy/SiO ${ }_{2}$ nanoparticles (5 wt\%) composites, the serious crack happens under low strain rate, which shows several crevices and is loose texture in appearance. On the opposite, under the high strain rates, the regular crazes occur, and there are hardly tiny cracks that can be noticed. The samples after test still keep hard quality. There is no obvious deformation, because the suitable content $\mathrm{SiO}_{2}$ nanoparticles can increase the interface strength of composites, which indicates that the composites can absorb more energy with smaller deformation.

\section{Conclusion}

The impact compression, including quasi-static and high strain rate compression properties of epoxy with various $\mathrm{SiO}_{2}$ nanoparticles contents $(0 \mathrm{wt} \%, 5 \mathrm{wt} \%, 10 \mathrm{wt} \%$ and $15 \mathrm{wt} \%)$ was investigated via split Hopkinson pressure bar (SHPB). The compression stress vs. strain curves of the composites with various $\mathrm{SiO}_{2}$ nanoparticles contents have been obtained and compared with those for quasi-static compression. The stress strain curves are strain rate sensitive. For high strain rate loading, the failure stress of epoxy composites with various $\mathrm{SiO}_{2}$ nanoparticles contents is much larger than that in quasi-static loading, while compressive stiffness of composites with $\mathrm{SiO}_{2}$ nanoparticles contents under various strain rates is much smaller than that of the composites without $\mathrm{SiO}_{2}$ nanoparticles. And the compressive stiffness of composites under different strain rates is lower when the $\mathrm{SiO}_{2}$ nanoparticles contents increase. The fracture pictures of the damaged composites with different $\mathrm{SiO}_{2}$ nanopar- 


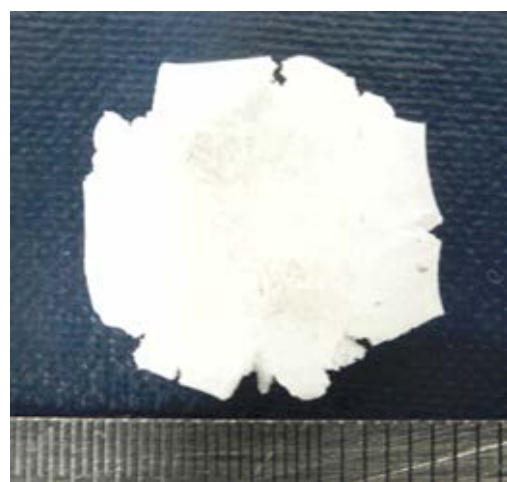

(a)

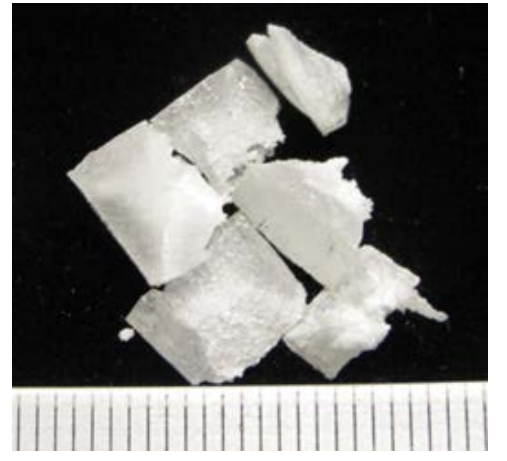

(c)

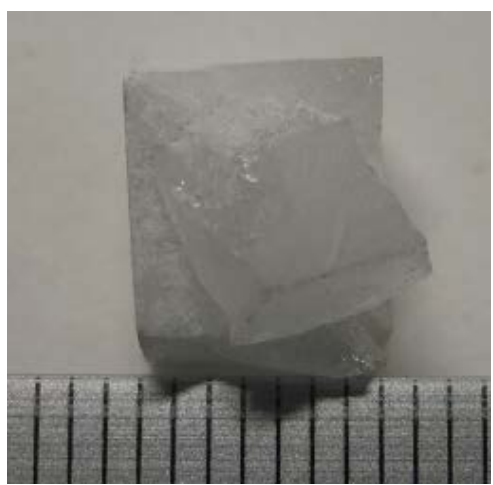

(b)

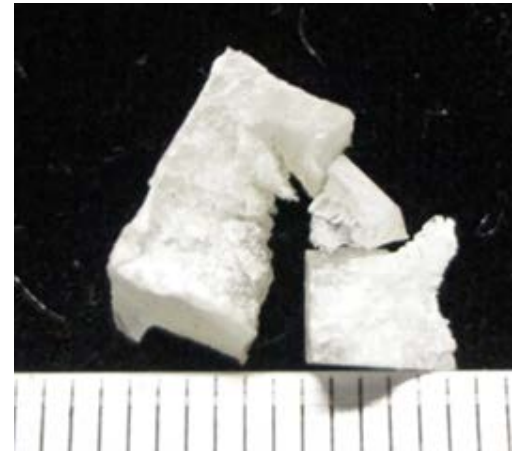

(d)

Figure 13. Compression fractures of epoxy/ $\mathrm{SiO}_{2}$ (10 wt\%) composites at various strain rates. (a) $0.001 / \mathrm{s}$; (b) $800 / \mathrm{s}$; (c) $1400 / \mathrm{s}$; (d) $2000 / \mathrm{s}$.

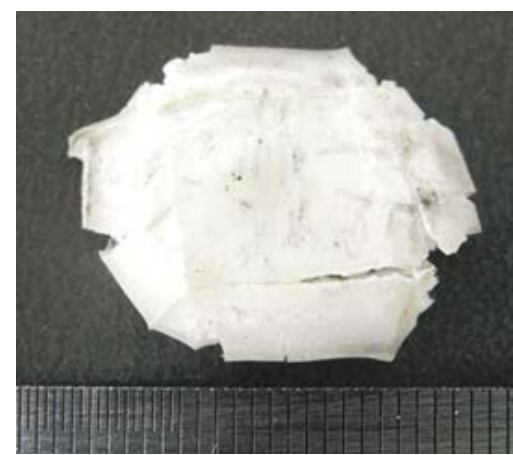

(a)

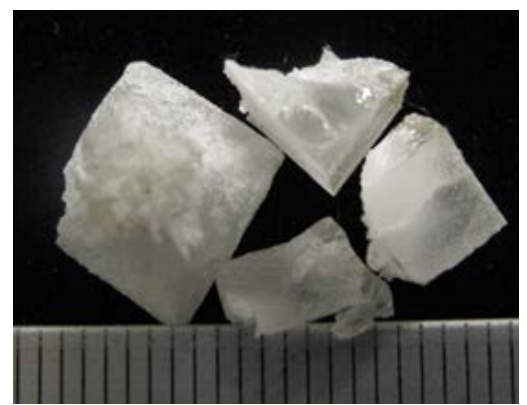

(c)

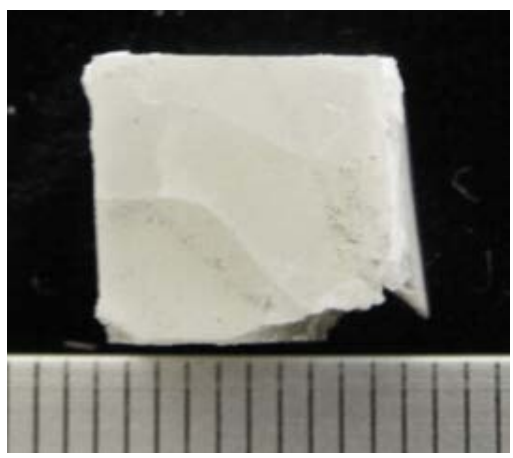

(b)

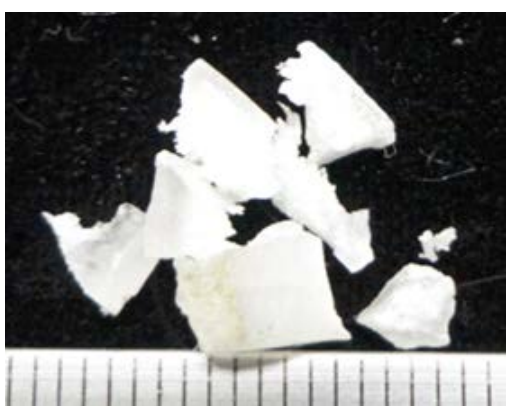

(d)

Figure 14. Compression fractures of epoxy/ $\mathrm{SiO}_{2}$ (15 wt\%) composites at various strain rates. (a) $0.001 / \mathrm{s}$; (b) $800 / \mathrm{s}$; (c) $1400 / \mathrm{s}$; (d) 2000/s. 
ticles contents at various strain rates show the different crack situations and morphology of the specimens. The cracks happened drastically with the increase of the $\mathrm{SiO}_{2}$ nanoparticles contents under $0.001 / \mathrm{s}$, and on the contrary, there were less crazes and the morphology became more stable with the increase of the $\mathrm{SiO}_{2}$ nanoparticles contents under high strain rates. The composites with higher contents of $\mathrm{SiO}_{2}$ nanoparticles improved the energy absorption of composites because they could elevate the roughness of composites. The mechanical parameters of composites with $\mathrm{SiO}_{2}$ nanoparticles contents at high strain rates could help the design of composites structures.

\section{Acknowledgements}

The authors acknowledge the financial support from the National Science Foundation of China (No. 11302085), the Fundamental Research Funds for the Central Universities (No. JUSRP1043 and JUSRP51404A), and the Innovation fund project of Cooperation among Industries, Universities \& Research Institutes of Jiangsu Province (No. BY2014023-34 and BY2014023-20).

\section{References}

[1] Rosso, P., Ye, L., Friedrich, K. and Sprenger, S. (2006) A Toughened Epoxy Resin by Silica Nanoparticle Reinforcement. Journal of Applied Polymer Science, 100, 1849-1855. http://dx.doi.org/10.1002/app.22805

[2] Johnsen, B., Kinloch, A., Mohammed, R., Taylor, A. and Sprenger, S. (2007) Toughening Mechanisms of Nanoparticle-Modified Epoxy Polymers. Polymer, 48, 530-541. http://dx.doi.org/10.1016/j.polymer.2006.11.038

[3] Deng, S., Ye, L. and Friedrich, K. (2007) Fracture Behaviours of Epoxy Nanocomposites with Nano-Silica at Low and Elevated Temperatures. Journal of Materials Science, 42, 2766-2774. http://dx.doi.org/10.1007/s10853-006-1420-x

[4] Zheng, Y. and Ning, R. (2005) Study of $\mathrm{SiO}_{2}$ Nanoparticles on the Improved Performance of Epoxy and Fiber Composites. Journal of Reinforced Plastics and Composites, 24, 223-233. http://dx.doi.org/10.1177/0731684405043552

[5] Wang, K., et al. (2005) Epoxy Nanocomposites with Highly Exfoliated Clay: Mechanical Properties and Fracture Mechanisms. Macromolecules, 38, 788-800. http://dx.doi.org/10.1021/ma048465n

[6] Zhou, Y., Hosur, M., Jeelani, S. and Mallick, P. (2012) Fabrication and Characterization of Carbon Fiber Reinforced Clay/Epoxy Composite. Journal of Materials Science, 47, 5002-5012. http://dx.doi.org/10.1007/s10853-012-6376-4

[7] Ferreira, J., Reis, P., Costa, J. and Richardson, M. (2013) Fatigue Behaviour of Kevlar Composites with NanoclayFilled Epoxy Resin. Journal of Composite Materials, 47, 1885-1895. http://dx.doi.org/10.1177/0021998312452024

[8] Barbezat, M., et al. (2009) Fracture Behavior of GFRP Laminates with Nanocomposite Epoxy Resin Matrix. Journal of Composite Materials, 43, 959-976. http://dx.doi.org/10.1177/0021998308100799

[9] Uddin, M.F. and Sun, C. (2008) Strength of Unidirectional Glass/Epoxy Composite with Silica Nanoparticle-Enhanced Matrix. Composites Science and Technology, 68, 1637-1643. http://dx.doi.org/10.1016/j.compscitech.2008.02.026

[10] Tsai, J.L., Hsiao, H. and Cheng, Y.L. (2010) Investigating Mechanical Behaviors of Silica Nanoparticle Reinforced Composites. Journal of Composite Materials, 44, 505-524. http://dx.doi.org/10.1177/0021998309346138

[11] Ma, P., Zhang, F., Gao, Z., Jiang, G. and Zhu, Y. (2014) Transverse Impact Behaviors of Glass Warp-Knitted Fabric/ Foam Sandwich Composites through Carbon Nanotubes Incorporation. Composites Part B: Engineering, 56, 847-856. http://dx.doi.org/10.1016/j.compositesb.2013.09.013

[12] Ma, P., Zhang, F., Jiang, G., Gao, Z. and Xia, D. (2014) Transverse Impact Characterization of Carbon Woven FabricFoam Sandwich Composites with Carbon Nanotubes. Fibers and Polymers, 15, 1560-1566. http://dx.doi.org/10.1007/s12221-014-1560-6

[13] Ma, P., Jiang, G., Chen, Q., Cong, H. and Nie, X. (2015) Experimental Investigation on the Compression Behaviors of Epoxy with Carbon Nanotube under High Strain Rates. Composites Part B: Engineering, 69, 526-533. http://dx.doi.org/10.1016/j.compositesb.2014.09.038 